Scientific Review - Engineering and Environmental Sciences (2021), 30 (3), 451-463

Sci. Rev. Eng. Env. Sci. (2021), 30 (3)

Przegląd Naukowy - Inżynieria i Kształtowanie Środowiska (2021), 30 (3), 451-463

Prz. Nauk. Inż. Kszt. Środ. (2021), 30 (3)

http://iks.pn.sggw.pl

DOI 10.22630/PNIKS.2021.30.3.38

Osamah H. CHAFAT, Sahar Basim Al-GHURAB, Basim H. Al-HUMEIDAWI

University of Al-Qadisiyah, College of Engineering

\title{
Investigation the effect of newly used polymer modified bitumen on the performance of hot mix asphalt containing reclaimed asphalt pavement
}

Key words: creep compliance, rutting, recycling old pavement, novolac, hexamine

\section{Introduction}

Reclaimed asphalt pavement (RAP) is widely employed as a replacement for natural aggregates in road pavements in recent decades. In new mixtures, it has advantages of minimizing amount of raw materials used, reducing costs and reducing environmental damage. Many studies have been conducted on hot mix asphalt (HMA) incorporating RAP, ranging from mix design to performance assessment. Also, they investigated the impact of a increasing of the \% RAP in new asphalt mixtures and found that HMA containing percentage of RAP can perform as well as or better than mixes comprised entirely fresh material (Al-Bayati, Tighe \& Achebe, 2018; Mirhosseini, Tahami, Hoff, Dessouky \& Ho, 2019; Zhu,
Ma \& Dong, 2020). The impact of polymer on performance of RAP-containing mixtures has also been studied in the literature (Daryaee, Ameri \& Mansourkhaki, 2020; Wang et al., 2020). Some researchers reported, it is possible to produce HMA with a high RAP content and acceptable mechanical properties, however, thermal cracking resistance, fatigue resistance need further investigation (Leiva-Villacorta, Taylor \& Willis, 2017).

Zhou, Gu, Jiang, Ni and Jiang (2019) studied the effect of RAP on the fatigue resistance of PMB mixtures. Their results showed that the increasing of RAP materials leads to increasing in fatigue life of mixtures. Pradhan and Sahoo (2020) examined the volumetric and mechanical properties of eleven mixes, five of them contained 30-70\% RAP with softer binder, five mixes containing RAP with a rejuvenator, and one control mix. They found that, all mixes met the specifica- 
tions of Superpave method. Ishaq and Giustozzi (2020) evaluated effects of adding RAP and a rejuvenator on freeze/ /thaw and moisture damage of HMA, using 20\% RAP. Their results showed that using rejuvenator can help in decreasing the deteriorating of RAP mixtures and decrease the impacts of freeze/thaw and moisture damage of HMA. Ma et al. (2020) observed an improving in moisture resistance and cracking of mixes containing RAP heated to higher temperature. Montanez, Caro, Carrizosa, Calvo and Sanchez (2020) demonstrated that the mechanical responses and performance of HMA containing RAP vary significantly with RAP sources.

Polymer modified bitumen (PMB) is widespread in last years. It improves general characteristic of HMA prepared with it as well as the long term performance (Plati, 2019). Due to the higher initial and maintenance cost of flexible pavement, PMB and RAP showed to become more cost-effective in terms of fatigue life than conventional mixes (Souliman, Mamlouk \& Eifert, 2016).

Kodippily, Holleran and Henning (2016) investigated the impact of adding RAP and PMB on HMA performance by preparing six mixtures with $\mathrm{PMB}$ and RAP at $0 \%, 15 \%$, and $30 \%$. Their results revealed that the mixture, which contains high percentage of RAP and PMB, meets the requirements of mechanical properties and sustainability of roads. Liphardt, Król and Radziszewski (2016) studied the effect of RAP which already contain $\mathrm{PMB}$ on rutting resistance in stone mastic asphalt (SMA) mixtures. It has been observed that adding more RAP-modified binders to asphalt mixes improves rutting resistance. Porot, Broere, Wis- tuba and Grönniger (2017) focused on evaluation the performance of mixture containing high percentage of RAP up to $70 \%$ with a bio-based rejuvenator agents. They found that the stiffness modulus was higher than the control mix and the rejuvenator agents improve the performance of HMA at high temperatures. It has been found that asphalt mixtures containing a low to medium ratio of RAP, often less than $25 \%$, can perform as well as or better than mixes prepared with new materials (McDaniel \& Nantung, 2005).

The current study focuses on investigation the effect of inclusion RAP in HMA up to $70 \%$. The replacement was conducted for all sizes of aggregate particle in HMA. The study involved using PMB prepared with novolac (phenol formaldehyde solid resin) and it cross-linking agent (hexamine). This polymer is very limit and not previously used with HMA containing RAP.

\section{Materials}

\section{Reclaimed asphalt pavement (RAP)}

Reclaimed asphalt pavement material was collected from an old highway pavement connected Al-Diwainyah and Najaf cities (Iraq). The binder content and gradation of RAP were calculated after extracting the bitumen from RAP according to the ASTM D2172 standard (ASTM International [ASTM], 2017). The percentage of asphalt binder in RAP was found to be $2.92 \%$. The physical properties and gradation of RAP materials can be found in previous article by authors (Al-Ghurabi \& Al-Humeidawi, 2021). 


\section{Bitumen and aggregates}

AC 40-50 was used as conventional bitumen. It physical properties and consistency tests results were reported in previous article by authors (Al-Ghurabi \& Al-Humeidawi, 2021). The aggregates were crushed limestone with nominal maximum size of $12.5 \mathrm{~mm}$. Limestone dust was used as mineral filler. The gradation, physical and chemical properties of aggregate and mineral filler were reported in previous article by authors (AlGhurabi \& Al-Humeidawi, 2021).

\section{Polymer}

Novolac with cross-linking agent (hexamine) was utilized in this research to modify pure bitumen. The percentage of addition of novolac was 3\% of weight of bitumen, and hexamine was added as $10 \%$ of weight of novolac. These percentages were selected according to several trials of asphalt binder consistency tests. The procedure of preparing PMB was found elsewhere (Al-Humeidawi, Medhlom, kadhim Hameed \& Kadhim, 2018).

\section{Methodology of the work}

\section{Mix design}

The mixtures were produced using Marshall mix design technique according to the AASHTO T245 standard (American Association of State Highway and Transportation Officials [AASHTO], 2015). Optimum binder content (OBC) was found to be $(4.7 \%)$ by total weight of mix. The experiments were carried out in two stages: the first stage involved, in addition to control mix, designing and preparing seven mixes with different $\%$ RAP $(10 \%, 20 \%, 30 \%, 40 \%$, $50 \%, 60 \%$, and $70 \%$ ) and conventional bitumen. These mixes were tested to predict their volumetric, mechanical, and performance characteristics. The second stage involved repeat preparing these mixes using PMB and the same tests were conducted for HMA mixes prepared with PMB.

\section{Laboratory test}

Four tests were included in this experimental program. The first test was Marshall stability which was conducted according to the ASTM D6927 standard (ASTM, 2015), the second test was indirect tensile strength (ITS) test which was conducted according to the AASHTO T283 standard (AASHTO, 2007), the third test was creep compliance test which was conducted according to the AASHTO T322 standard (AASHTO, 2011) and used to evaluate the stiffness and fatigue cracking resistance of HMA. This test was conducted by applying constant load for $100 \mathrm{~s}$ at temperature of $0^{\circ} \mathrm{C}$, where two LVDTs were used to measure horizontal strain and one for vertical strain. The last test was wheel track test which was conducted according to the BSEN 12697-22 standard (British Standard Institution [BSI], 2003) and used to evaluate the permanent deformation of mix (rutting). This test was conducted by applying 10,000 cycles of loading on each specimen at temperature of $60^{\circ} \mathrm{C}$. The moisture susceptibility of mixes was evaluated by calculating the tensile strength ratio (TSR) according to the AASHTO T283 standard. 


\section{Results and discussion}

\section{Volumetric properties}

The volumetric properties of mixes were calculated using experimental tests results. These properties include air void $(\mathrm{AV})$, voids in mineral aggregate (VMA), and voids filled with asphalt (VFA). The table illustrates the values of volumetric properties of HMA containing RAP with conventional and PMB binder. All volumetric properties were within the requirement limits. The AV are slightly increased with using PMB that may be related to increasing the viscosity of bitumen. The values of other properties have been changed accordingly. According to results of volumetric properties, all percentages of replacement can be adopted.

\section{Marshall stability test}

Figure 1 shows the results of Marshall stability for HMA involved re- placing the virgin aggregate with different content of RAP up to $70 \%$ with an increment of $10 \%$. The replacement included the retained aggregate on all sieves of coarse and fine aggregate with the adopted ratio. The values of Marshall stability is increased with using RAP especially at $10 \%$ and $50 \%$ RAP. These percentages of increases were $11 \%$ and $13 \%$ for mix with $10 \%$ and $50 \%$ RAP respectively for specimens prepared with conventional binder. The Marshall stability decreases with increasing RAP content up to $30 \%$ RAP, after that, Marshall stability increases again up to $50 \%$ RAP then decreases again. This response can be explained by, as a percentage of RAP replacement increases the ratio of aged asphalt increased which causes a reduction in Marshall stability, after 40\% RAP replacement, the contribution of coarse aggregate increases which comprises $52 \%$ of total aggregate compared with fine aggregate which comprises $41 \%$ of total aggregate and lead to increases in

TABLE. Volumetric properties of HMA containing RAP

\begin{tabular}{|c|c|c|c|c|c|c|}
\hline \multirow{4}{*}{$\%$ RAP } & \multicolumn{2}{|c|}{$\mathrm{AV} \%$} & \multicolumn{2}{|c|}{ VMA\% } & \multicolumn{2}{|c|}{ VFA $\%$} \\
\hline & $\begin{array}{l}\text { conventional } \\
\text { binder }\end{array}$ & $\begin{array}{l}\text { PMB } \\
\text { binder }\end{array}$ & $\begin{array}{l}\text { conventional } \\
\text { binder }\end{array}$ & $\begin{array}{l}\text { PMB } \\
\text { binder }\end{array}$ & $\begin{array}{l}\text { conventional } \\
\text { binder }\end{array}$ & $\begin{array}{l}\text { PMB } \\
\text { binder }\end{array}$ \\
\hline & \multicolumn{6}{|c|}{ acceptable limits } \\
\hline & \multicolumn{2}{|c|}{ (3-5) (SCRB, 2003) } & \multicolumn{2}{|c|}{$\geq 14$ (SCRB, 2003) } & \multicolumn{2}{|c|}{$\begin{array}{c}\text { (65-75) (Asphalt Institute } \\
\text { [AI], 2014) } \\
\end{array}$} \\
\hline $0 \%$ & \multicolumn{2}{|c|}{4} & \multicolumn{2}{|c|}{15.1} & \multicolumn{2}{|c|}{73.5} \\
\hline $10 \%$ & 3.55 & 3.87 & 14 & 14.3 & 74.6 & 72.9 \\
\hline $20 \%$ & 3.99 & 4.4 & 14.37 & 14.7 & 72.23 & 70 \\
\hline $30 \%$ & 3.63 & 3.79 & 14 & 14.2 & 74 & 73.3 \\
\hline $40 \%$ & 3.67 & 4.1 & 14.1 & 14.5 & 73.9 & 71.7 \\
\hline $50 \%$ & 4.61 & 4.73 & 14.9 & 15 & 69.1 & 68.5 \\
\hline $60 \%$ & 4.77 & 4.8 & 15.1 & 15.1 & 68.41 & 68.2 \\
\hline $70 \%$ & 4.41 & 4.61 & 14.1 & 14.9 & 70 & 69 \\
\hline
\end{tabular}




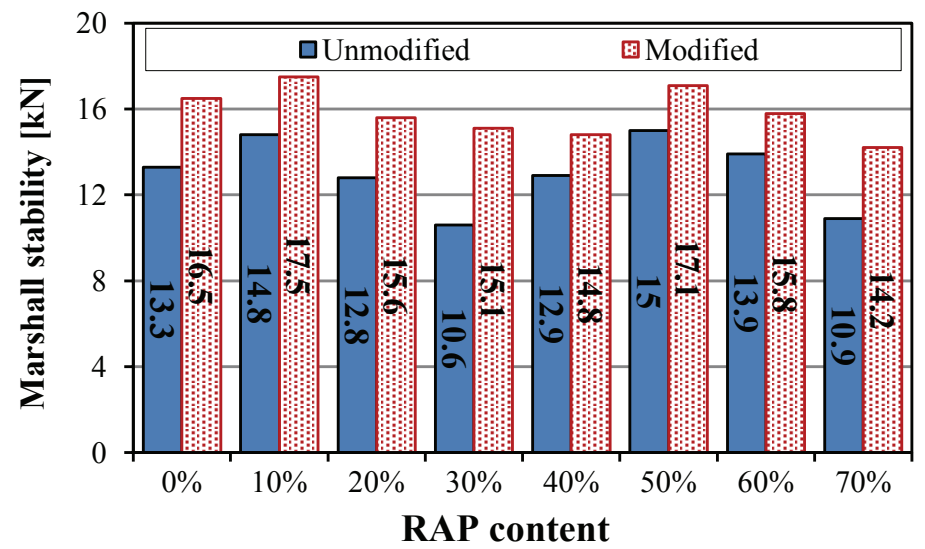

FIGURE 1. Marshall stability results for HMA contain different percentages of RAP

Marshall stability due to more mechanical interlock. With exceeding optimum value and replacing more than half the quantity of aggregate with RAP, the stability gradually decreases due to the contribution of more aged binder. For HMA prepared with PMB, it can be observed that all mixes have higher values of Marshall stability compared to mixes prepared with unmodified (conventional) binder. That is attributed to high viscosity of PMB binder resulting from modifying the binder with polymer. The trend of changing Marshall stability with RAP content is similar to that of unmodified bitumen for the same reason, however, the percentage of reduction is less than that of unmodified asphalt binder due to using PMB. For all mixes with conventional and PMB, Marshall flow values were in a range of 2-4 $\mathrm{mm}$ which is with the specifications of the State Roads and Bridges Corporation (SCRB, 2003).

\section{Indirect tensile strength test (ITS)}

Figure 2 shows the results of ITS for unconditioned and conditioned specimens of HMA mixes prepared with different percentages of RAP and unmodi-

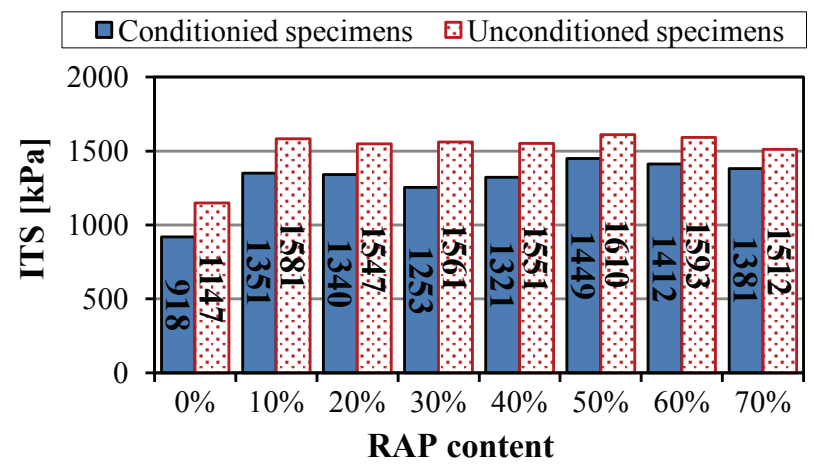

FIGURE 2. ITS test values for specimens with different percentages of RAP and conventional bitumen 
fied bitumen. The use of RAP for all percentages of replacement significantly improves the ITS values for both unconditioned and conditioned specimens of HMA mixes. That is maybe attributed to existing of a hardening binder that has a higher viscosity which consequently increases the adhesion between the aggregate particles. The maximum value of ITS for both unconditioned and conditioned specimens of HMA mixes was achieved at 50\% RAP replacement in a similar trend to that observed in Marshall stability test. Figure 3 presents the results of ITS for unconditioned and conditioned specimens of HMA mixes prepared with different percentages of RAP and PMB.
The use of PMB improves ITS values especially for condition specimens due to more adhesion between aggregate particles. No significant variation in ITS values was observed between conditioned specimens with different percentages of RAP due to using PMB, which provides more adhesion between mix components. Figure 4 illustrates TSR for specimens prepared with conventional and PMB binder, and contain different percentages of RAP. All mixes showed TSR more than $80 \%$ which represents a minimum limit according to AASHTO T283. The use of PMB significantly improves TSR values of all mixes with an optimum value obtained at 50\% RAP.

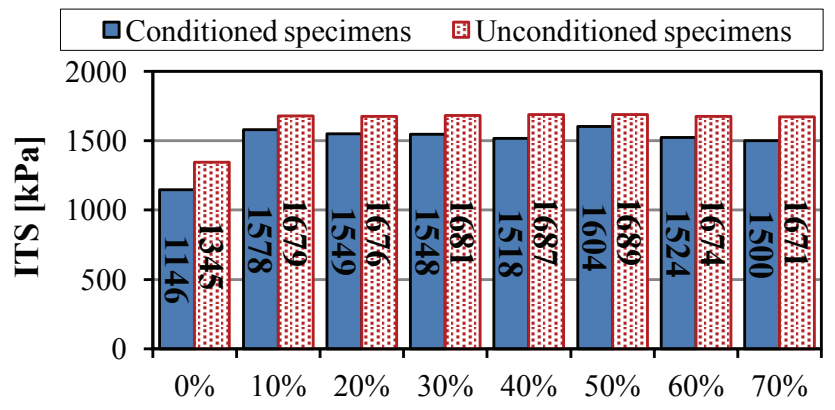

RAP content

FIGURE 3. ITS test values for specimens with different percentages of RAP and PMB binder

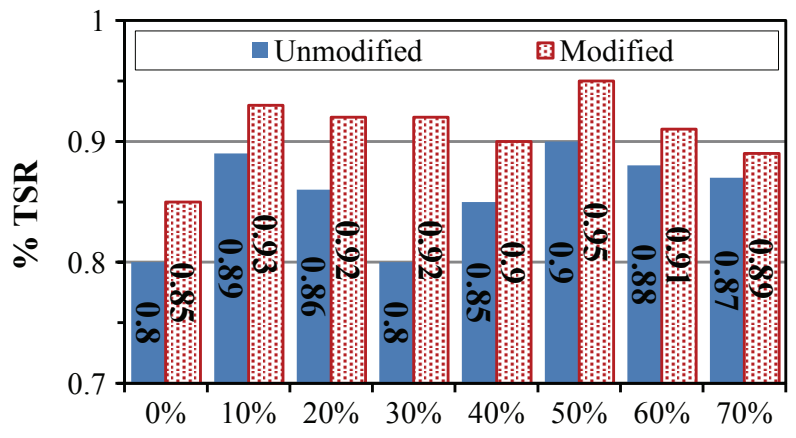

RAP replacement

FIGURE 4. TSR values for modified and unmodified specimens with different percentages of RAP 


\section{Creep compliance}

The creep compliance test was conducted at temperature of $0^{\circ} \mathrm{C}$ as shown in Figure 5. Figure 6 illustrates the results of creep compliance for control and HMA mixes prepared with different percentage of RAP and unmodified bitumen. Figure 7 illustrates the results of creep compliance for HMA mix prepared with different percentage of RAP and PMB, while Figure 8 shows the final results of creep compliance for samples with conventional and PMB. Form these figures it can be observed that the using of all investigated percentages of RAP reduce the values of creep compliance compared with control mix. That may be related to higher vis-

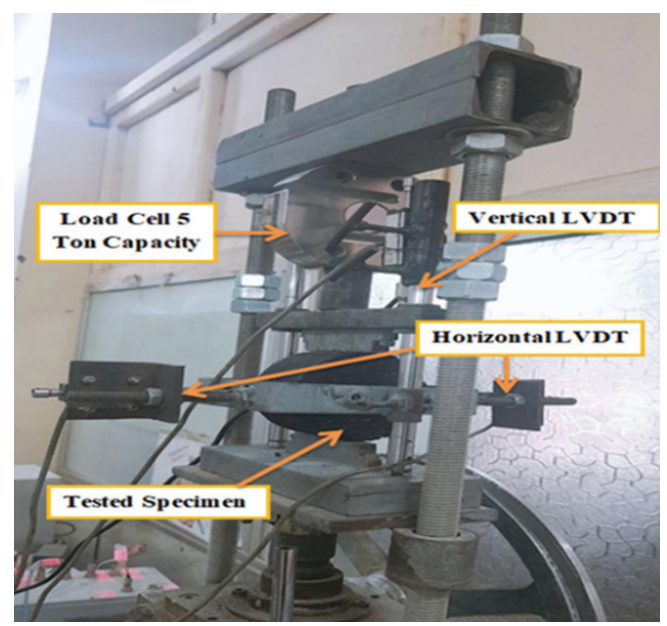

FIGURE 5. Test machine for creep compliance

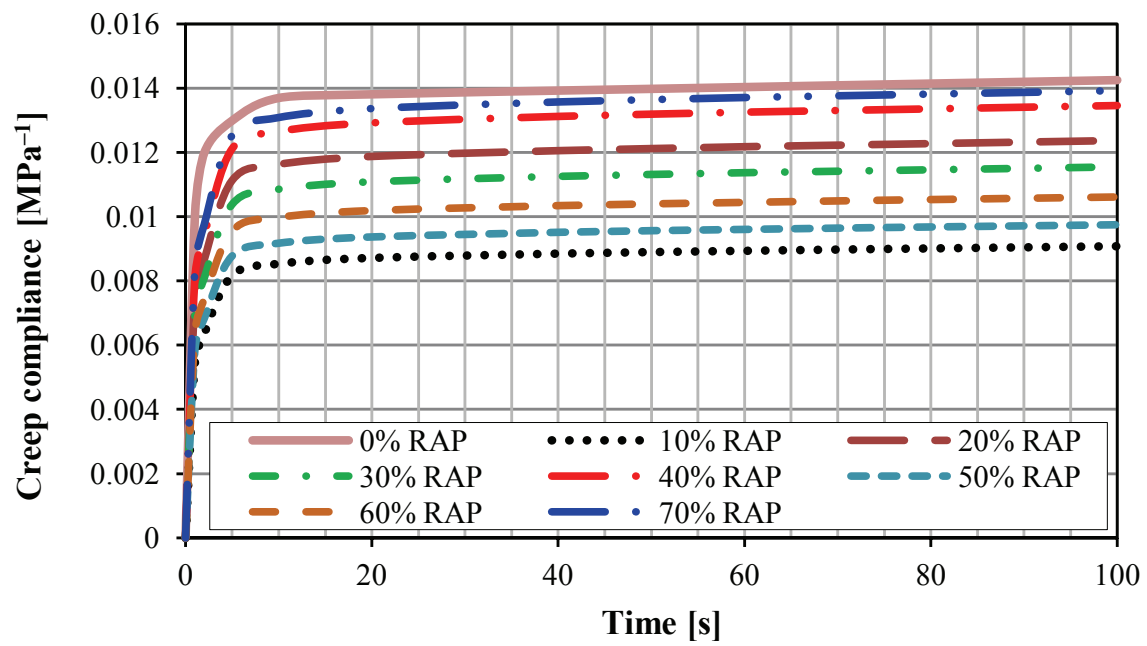

FIGURE 6. Creep compliance for HMA contained different percentages of RAP and conventional bitumen 


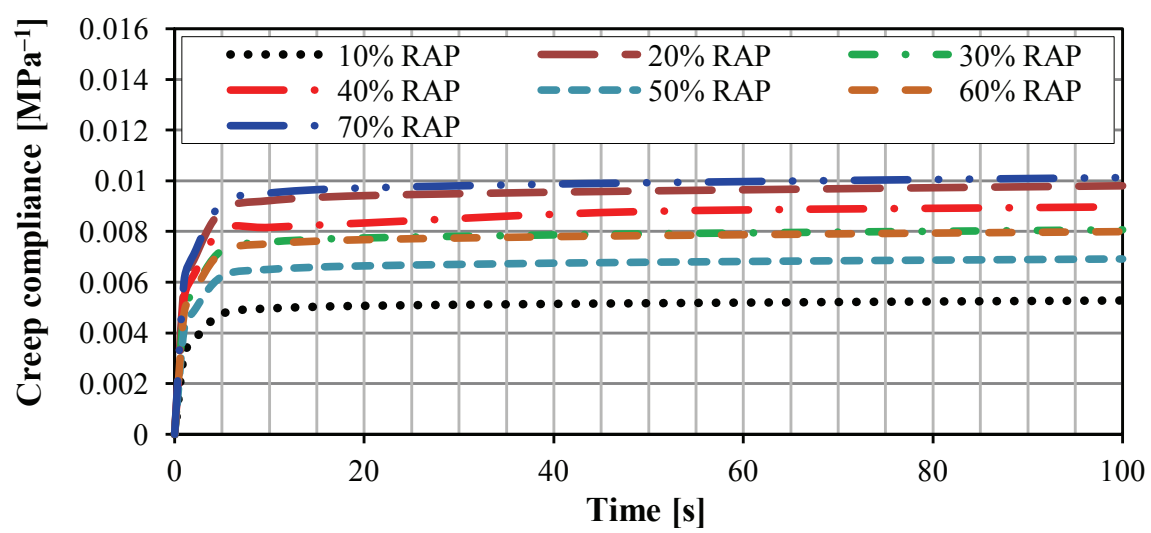

FIGURE 7. Creep compliance for HMA contained different percentages of RAP and PMB

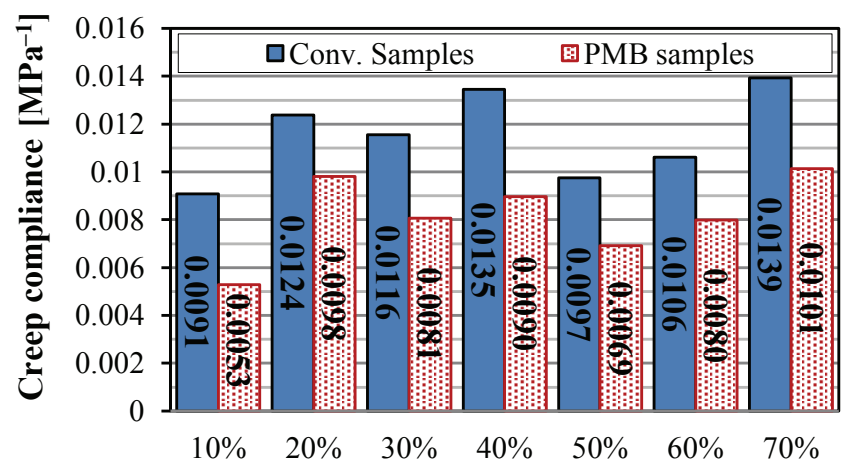

RAP replacement

FIGURE 8. Creep compliance for HMA mixes with conventional and PMB

cosity of hardened binder and less porosity of RAP aggregate which reduces the asphalt binder absorption. Also, the using of PMB significantly reduces the creep compliance values for all percentages of RAP replacement which is an indication of increase the stiffness of HMA and increases the cracks resistance. That may be related to more adhesion between aggregate particles provided by PMB. The lower creep compliance values were obtained at percentages of RAP replacement of $10 \%$ and $50 \%$ in similar trend to what were observed in previous tests.

\section{Wheel track test (WTT)}

Wheel track test was conducted according to the BS EN 12697-22 standard, using wheel track testing machine shown in Figure 9. The specimens were nine, one specimen was for control mix, four specimens with conventional binder and four different percentages of RAP $(10 \%, 30 \%$, $50 \%$, and $70 \%$ ) and four specimens with PMB binder and four different percentages of RAP $(10 \%, 30 \%, 50 \%$, and $70 \%)$. Figures 10, 11 and 12 show the results of rut depth for all previously mentioned 


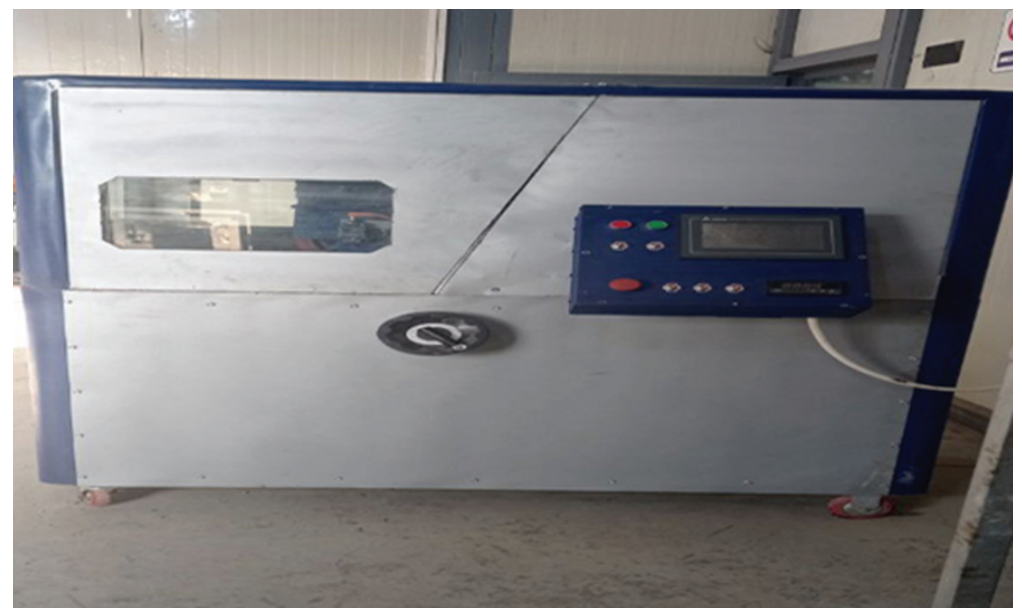

FIGURE 9. Wheel track testing machine

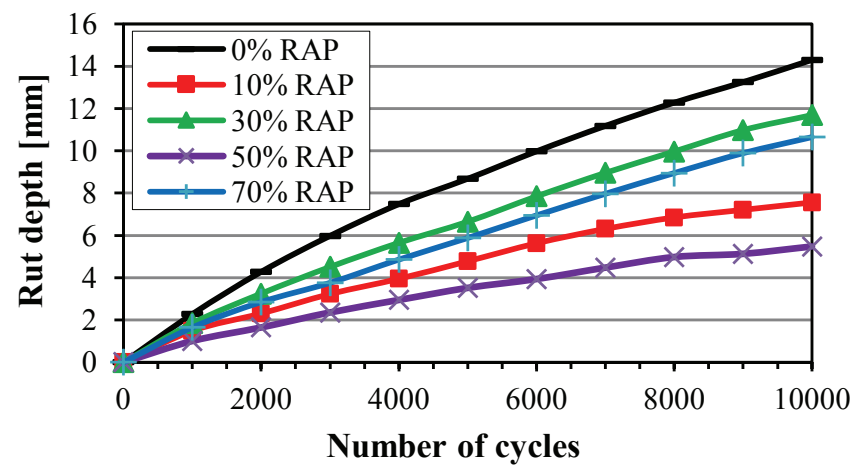

FIGURE 10. Effect of RAP content on rut depth for specimens prepared with conventional binder

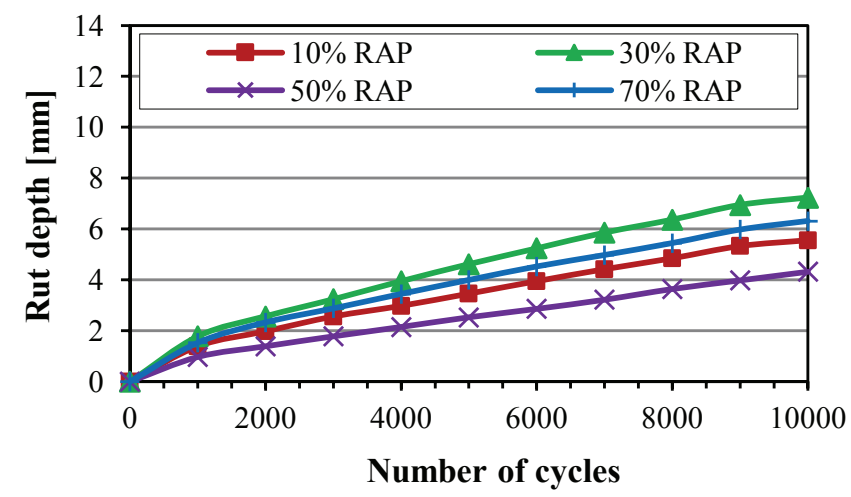

FIGURE 11. Effect of RAP content on rut depth for specimens prepared with PMB binder 


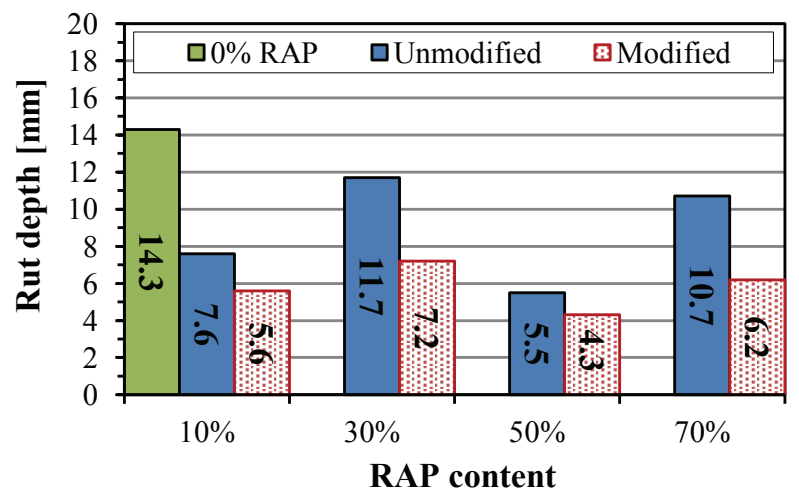

FIGURE 12. Final rut depth values for all HMA mixes with different percentage of RAP, and with conventional and PMB binder

specimens. The results showed that the using of RAP reduces the rut depth compared with control mix. Significant reduction was observed with $\mathrm{PMB}$ instead of conventional binder. The lowest rutting depth was obtained at 50\% RAP replacement for both conventional and PMB binder. The percentages of reduction were reached up $38 \%$ and $30 \%$ for specimens contains 50\% RAP, and prepared with conventional and PMB binder respectively compared with control mix. The increase in binder stiffness constrains the ability of the aggregate particles to slide or move even on a micro-scale due to the high viscosity of hardened and
PMB binder which improves the rutting resistance of HMA. Figure 13 shows pictures for tested specimens.

\section{Conclusions}

Based on the results of this study, the following conclusions can be drawn:

1. The using of PMB binder prepared by adding novolac and hexamine to conventional bitumen, can significantly improve the performance of HMA contained RAP. This type of PMB is used for first time with HMA contained RAP.
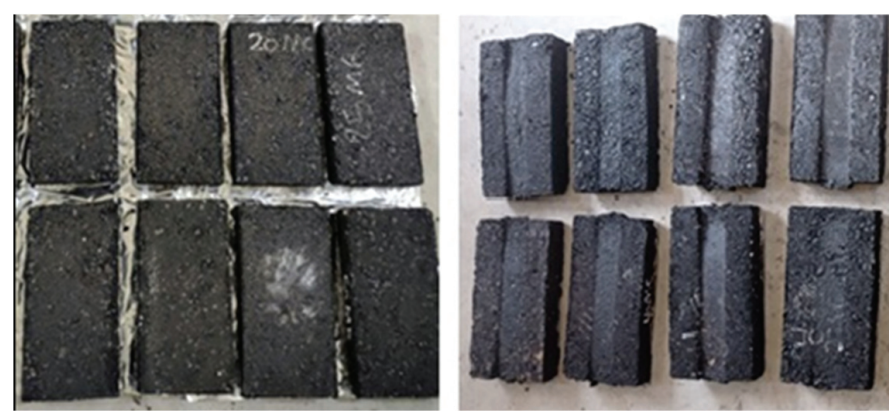

FIGURE 13. Sample preparation and testing for wheel track test 
2. In general, the incorporation of RAP material in various percentages, as well as PMB in this study, improves mechanical properties and performance of HMA (Marshall stability, ITS, moisture damage resistance, resistance for permenant deformation, i.e. ruting, and fatigue life).

3. According to results of this study, it was found that the $50 \%$ RAP replacement is the optimum percentage of RAP replacment in HMA. Using of 50\% RAP resulted in maximum increasing in ITS values for both unconditioned and conditioned samples. This improvement leads to high resistance to moisture damage of HMA measured in term of TSR and consequently less stripping for mix components.

4. From the creep compliance test, the incorporation of RAP materials and PMB reduce the creep compliance values for all percentages of RAP replacement which is an indication of increasing stiffness of HMA and improves the fatigue life.

5. The inclusion of RAP materials and PMB improved rutting resistance of HMA. The rut depth values of HMA contained RAP and PMB significantly reduced compared with the control mix. The lowest rutting depth was obtained at 50\% RAP replacement for both conventional and PMB binder as the rut depth reduced to $38 \%$ and $30 \%$ of the control mix value for unmodified and PMB mixes respectively.

6. Results of experimental work indicated that all HMA which prepared with RAP and PMB resulted in better performance compared to HMA contianed entirely fresh aggregate and conventional binder due to high viscosity of RAP and PMB which leads to an increase in the stiffness of HMA.

\section{References}

Al-Bayati, H.K.A., Tighe, S.L. \& Achebe, J. (2018). Influence of recycled concrete aggregate on volumetric properties of hot mix asphalt. Resources. Conservation and Recycling, 130, 200-214.

Al-Ghurabi, S.B. \& Al-Humeidawi, B.H. (2021). Comparative evaluation for the effect of particles size of reclaimed asphalt pavement (RAP) on the properties of HMA. Journal of Physics: Conference Series, 1895(1), 012025. https://doi.org/10.1088/1742-6596/ 1895/1/012025

Al-Humeidawi, B.H., Medhlom, M.K., kadhim Hameed, K. \& Kadhim, H.K. (2018). Production of hard grade bitumen for using in high modulus asphalt concrete. Journal of University of Babylon for Engineering Sciences, 26(6), 157-174.

American Association of State Highway and Transportation Officials [AASHTO] (2007). Standard method of test for resistance of compacted asphalt mixtures to moisture-induced damage (AASHTO T283). Washington: American Association of State Highway and Transportation Officials.

American Association of State Highway and Transportation Officials [AASHTO] (2011). Determining the creep compliance and strength of hot mix asphalt (HMA) using the indirect tensile test device (AASHTO T322). Washington: American Association of State Highway and Transportation Officials.

American Association of State Highway and Transportation Officials [AASHTO] (2015). Standard method of test for resistance to plastic flow of asphalt mixtures using Marshall apparatus (AASHTO T245). Washington: American Association of State Highway and Transportation Officials.

Asphalt Institute [AI] (2014). MS-2 asphalt mix design methods. Lexington (KY): Asphalt Institute. 
ASTM International [ASTM] (2015). Standard test method for Marshall stability and flow of asphalt mixtures (ASTM D6927-15). West Conshohocken (PA): ASTM International.

ASTM International [ASTM] (2017). Standard test methods for quantitative extraction of asphalt binder from asphalt mixtures (ASTM D2172). West Conshohocken (PA): ASTM International.

British Standard Institution [BSI] (2003). Bituminous mixtures. Test methods for hot mix asphalt (BS EN 12697-22). London: British Standard Institution.

Daryaee, D., Ameri, M. \& Mansourkhaki, A. (2020). Utilizing of waste polymer modified bitumen in combination with rejuvenator in high reclaimed asphalt pavement mixtures. Construction and Building Materials, 235, 117516. https://doi.org/10.1016/j.conbuildm at.2019.117516

Ishaq, M.A. \& Giustozzi, F. (2020). Rejuvenator effectiveness in reducing moisture and freeze/ /thaw damage on long-term performance of 20\% RAP asphalt mixes: An Australian case study. Case Studies in Construction Materials, 13, e00454. https://doi.org/10.1016/ j.cscm.2020.e00454

Kodippily, S., Holleran, G. \& Henning, T.F.P. (2016). Deformation and cracking performance of recycled asphalt paving mixes containing polymer-modified binder. Road Materials and Pavement Design, 18(2), 425-439.

Leiva-Villacorta, F., Taylor, A. \& Willis, R. (2017). High-modulus asphalt concrete (HMAC) mixtures for use as base course. Auburn (AL): National Center for Asphalt Technology Report at Auburn University.

Liphardt, A., Król, J. \& Radziszewski, P. (2016). Influence of polymer modified binder content from RAP on stone mastic asphalt rutting resistance. Procedia Engineering, 153, 407-413.

Ma, Y., Polaczyk, P., Park, H., Jiang, X., Hu, W. \& Huang, B. (2020). Performance evaluation of temperature effect on hot in-place recycling asphalt mixtures. Journal of Cleaner Production, 277, 124093. https://doi.org/10.1016/ j.jclepro.2020.124093
McDaniel, R. \& Nantung, T. (2005). Designing superpave mixes with locally reclaimed asphalt pavement. TR NEWS, 239, 28-30.

Mirhosseini, A.F., Tahami, S.A., Hoff, I., Dessouky, S. \& Ho, C.H. (2019). Performance evaluation of asphalt mixtures containing high-RAP binder content and bio-oil rejuvenator. Construction and Building Materials, 227, 116465. https://doi.org/10.1016/j.conbu ildmat.2019.07.191

Montanez, J., Caro, S., Carrizosa, D., Calvo, A. \& Sanchez, X. (2020). Variability of the mechanical properties of Reclaimed Asphalt Pavement (RAP) obtained from different sources. Construction and Building Materials, 230, 116968. https://doi.org/10.1016/ j.conbuildmat.2019.116968

Plati, C. (2019). Sustainability factors in pavement materials, design, and preservation strategies: a literature review. Construction and Building Materials, 211, 539-555.

Porot, L., Broere, D., Wistuba, M. \& Grönniger, J. (2017). Asphalt and binder evaluation of asphalt mix with $70 \%$ reclaimed asphalt. Road Materials and Pavement Design, 18(sup2), 66-75.

Pradhan, S.K. \& Sahoo, U.C. (2020). Influence of softer binder and rejuvenator on bituminous mixtures containing reclaimed asphalt pavement (RAP) material. Journal of Transportation Science Technology (in press).

Souliman, M.I., Mamlouk, M. \& Eifert, A.J.P.E. (2016). Cost-effectiveness of rubber and polymer modified asphalt mixtures as related to sustainable fatigue performance. Procedia Engineering, 145, 404-411.

State Corporation of Roads and Bridges [SCRB] (2003). General specifications for roads and bridges. Baghdad: State Corporation of Roads and Bridges, Ministry of Housing and Construction, Republic of Iraq.

Wang, J., Qin, Y., Xu, J., Zeng, W., Zhang, Y., Wang, W., \& Wang, P. (2020). Crack resistance investigation of mixtures with reclaimed SBS modified asphalt pavement using the SCB and DSCT tests. Construction and Building Materials, 265, 1-8.

Zhou, Z., Gu, X., Jiang, J., Ni, F., \& Jiang, Y. (2019). Fatigue cracking performance evaluation of laboratory-produced polymer modi- 
fied asphalt mixture containing reclaimed asphalt pavement material. Construction and Building Materials, 216, 379-389.

Zhu, J., Ma, T. \& Dong, Z. (2020). Evaluation of optimum mixing conditions for rubberized asphalt mixture containing reclaimed asphalt pavement. Construction and Building Materials, 234, 117426. https://doi.org/10.1016/ j.conbuildmat.2019.117426

\section{Summary}

Investigation the effect of newly used polymer modified bitumen on the performance of hot mix asphalt containing reclaimed asphalt pavement. The current research focuses on investigating the effect of using reclaimed asphalt pavement (RAP) on performance of hot mix asphalt (HMA) prepared with polymer modified bitumen (PMB) binder. This PMB used for the first time with HMA contained RAP. The mechanical properties and performance of HMA were assessed using several standard tests including Marshall, indirect tensile strength, creep compliance, and wheel track test. The RAP replacement was conducted up to $70 \%$ of total aggregate in HMA with an increment of $10 \%$. The results of investigation showed, that the use of PMB binder prepared by addition novolac (phenol formaldehyde solid resin) and hexamine to conventional bitumen, significantly improved the performance of HMA contained RAP. Also, the optimum percentage of RAP replacement was found to be $50 \%$ of total aggregate in HMA. For this level of replacement, the rut depth reduced up to $38 \%$ of its original value.

\section{Authors' address:}

Basim H. Al-Humeidawi - corresponding author (https://orcid.org/0000-0002-1566-5983)

University of Al-Qadisiyah

College of Engineering

Roads and Transport Engineering Department

Al-Jamaah Str., Al Diwaniyah

Iraq

e-mail: basim.alhumeidawi@qu.edu.iq 